\title{
A Study of Patent Open Source Strategies Based on Open Innovation: The Case of Tesla
}

\author{
Jianan Wang, Xiaobao Peng \\ School of Public Affairs, University of Science and Technology of China, Hefei, China \\ Email:wjn@mail.ustc.edu.cn
}

How to cite this paper: Wang, J. N., \& Peng, X. B. (2020). A Study of Patent Open Source Strategies Based on Open Innovation: The Case of Tesla. Open Journal of Social Sciences, 8, 386-394.

https://doi.org/10.4236/jss.2020.87031

Received: June 28, 2020

Accepted: July 28, 2020

Published: July 31, 2020

Copyright $\odot 2020$ by author(s) and Scientific Research Publishing Inc. This work is licensed under the Creative Commons Attribution International License (CC BY 4.0).

http://creativecommons.org/licenses/by/4.0/

(c) (i) Open Access

\begin{abstract}
Most high-tech companies take strict strategies to protect their patents, while traditional patent protection strategies often need to face the challenges such as the slow conversion of patented technology. The patent open source strategy is to free the patent to the user for free and is usually with conditions according to certain rules, such as GNU and GPL contracts, etc. This strategy greatly encourages technology sharing and innovation, and changes the logic of intellectual property protection. At present, the patent open source research in the computer field is relatively common but not yet matured in other hightech fields. Tesla is a representative of patent open source strategy in the field of non-computer high-tech. In addition to analyze Tesla's patent open source strategy, this article can also be referenced by other high-tech fields as well as China's new energy vehicle industry, and provides a reference for formulating long-term development strategies of which.
\end{abstract}

\section{Keywords}

Patent, Open-Source, Intellectual Property, Technological Standard, New Energy

\section{Introduction}

As an exclusive monopoly right granted by law to innovators, patents have been seen as a means of promoting economic development and enhancing the strategic competitiveness of enterprises. More and more companies are realizing the importance of patents and are protecting their intellectual property rights by applying for patents or even forming patent pools. However, a patent can only have value if it is applied. Individuals or enterprises outside of the patent owner's ownership that wish to apply a patent generally have to go through a complicated and lengthy negotiation process and obtain a patent license. This can lead 
to the slow development of the conversion and industrialization of patented technologies, which not only hinders the transfer and implementation of innovations, but also gives rise to problems in the patenting of existing technologies. The development of the project creates obstacles to the full and effective application of the value of the patent.

Patent open source, developed from the sharing of goods and software open source, is undoubtedly the most powerful support for technology sharing (Leveque \& Meniere, 2007). The focus of open source is “open”. Seeking common ground while reserving differences, mutual benefit and win-win situation, is the essence of open source. While open source encourages innovation and development, it also protects the intellectual property rights of original creators with legally binding agreements. Others are able to learn and apply these patents and rely on them to develop new products under the constraints of relevant agreements and rules, and no need to go through the lengthy process of patent licensing and negotiation. What's more, the fundamental of open source is the co-development of shared technology platform and individual participants. In terms of the dynamic evolution of the market game, open source is at the same time conductive, attracting large-scale participants, and motivating other peers to choose open source (Chen, 2018).

Since open source is derived from Computer Science area, the open source problem is focused more on software or hardware intellectual property issues than that of other areas of high technology (Taeihagh, 2017). What's more, the advantages of patent open source are not sufficiently noticed. The current opinion is mainly focused on shorting the negotiation process of patent licensing and promote the transformation of patented technology, but the advantages of patent open-source in improving the strategic competitiveness of enterprises, such as the implementation of technology standardization and other aspects, have not made a profound study yet (Chen, 2018). Furthermore, although patent open source can put an end to patent trolls, it poses other potential risks, such as undermining strategic competitiveness that patent holders and users, in particular, have to worry about (Maggiolino, 2013).

Tesla's strategy is a typical representative of a patent open source application in non-computer industries. Current research on Tesla's patent open source strategy focuses on how Tesla's patent open source strategy goes from propelling technology evolution to advancing the industry, and finally strengthening Tesla itself. Meanwhile, many articles have also discussed the rapid progress of Tesla's charging facilities, but ignored its linkage to the promotion of patent open source and technology standards unification, and were not aware of the sustainability issues of patent open source. For these reasons, this article will not analyze the patent open source model alone, but will combine it with the business case of Tesla at the same time. Then this article analyzes the reasons for Tesla's commercial success and the role of patent open source in it, discusses the sustainability of Tesla's patent open source strategy, reveals its successes and possible 
problems, and then draws some important conclusions from it.

\section{Tesla Business Model Analysis}

Tesla is the first electric vehicle company to open its patents. On June 12, 2014, the Tesla CEO Elon Musk announced that all patents owned by Tesla would be opened. As of 2019, Tesla has completed open-sourcing all of its patents at this stage. As the common code of open source, Tesla also adheres to GPL compliance principles, upload its in-vehicle system program's source code in 2018 to Github, a hosting platform for open source and private software projects, because this program was developed by open source development tools like the Linux Kernel.

Tesla has been developing electric cars since 2005. For the past 15 years, Tesla has been always in deficit and making few profits. However, instead of bankruptcy, Tesla has been able to attract a steady stream of money flow, even rushing to a market capitalization of around $\$ 200$ billion, the largest market capitalization of any global automotive company. This achievement confirms the success of Tesla's patent open-source oriented corporate business strategy as well as its Cross-Functional Combination model.

Tesla's Cross-Functional Combination model based on open source strategy consists of the following components:

\subsection{User Group Building}

Tesla's main market positioning is the urban middle-class group. These people are generally well-educated, have a strong ability to accept new things and a better sense of environmental protection, and have a certain consumption capability. Tesla's characters of high-end, stylish, energy-efficient, technology-filled functional design, and outstanding power perfectly fit their demand. As for the marketing business, Tesla currently provides services such as vehicle sales, technical maintenance and charging.

Tesla will also be able to maintain its users by convenient and fast charging service. As of March 2020, Tesla had deployed 1870 supercharging stations and 16,585 Superchargers in the worldwide, and all are continuing to grow. In the early years, Tesla used to offer customers free charging for the duration of their car cycle, yet this service was no longer available for customers joined after September 17, 2018, which was replaced by a free charging allowance of $400 \mathrm{kWh}$ per year. An automotive media Electrek estimated that it would bring Tesla an annual revenue of $\$ 50$ million to $\$ 100$ million in energy sales. Tesla has also designed a marketing strategy based on charging services: buying Tesla vehicles through referral programs, both referrals and new owners will be rewarded with a certain amount of charging credits.

\subsection{Financing}

Tesla has had a lot of success in the financial markets. In 2009, Tesla received 
several rounds of financing through pre-sales of Model S-Series model, getting $\$ 10$ million in pre-sale funding and 2000 pre-orders. In the same year, Tesla sold $10 \%$ of its shares and received a $\$ 50$ million from Daimler, the parent company of Mercedes-Benz. 2010 was another year. Accepted a $\$ 50$ million capital injection from Toyota, and on June 29 of that year, Tesla went public on the Nasdaq, via an IPO Achieving \$189 million in financing. This money gives Tesla, which is in its infancy, a good start.

In addition, Tesla is also actively creating capital flow through financial methods such as more waves of stock offering. In January 2020, the Tesla Shanghai Gigafactory started to assemble new cars, and the first batch of new cars rolled off from the production line. Subsequently, Tesla successfully issued an additional 2.65 million shares at $\$ 767$ per share in early February 2020 and raised approximately $\$ 2$ billion. As a result of all these good news, Tesla's stock surged, soaring to about $\$ 920$ per share in just one week, even squeezing many short sellers to hopelessness.

\subsection{R\&D (Research and Development)}

With sufficient funding, Tesla can reveal its strong R\&D capabilities and keen sense of patent layout. Referenced the analysis of Tesla's global patent application by Du et al. (2016), we can see that Tesla started global patent application in 2005 and has applied 28 patents in the following 2 years. Later, its patent applying was slowed down in 2008, possibly due to a technical bottleneck. But in 2009, Tesla began receiving a larger investment for a two-year period and made major breakthroughs in technology development, especially in battery, and the total amount of patent application in this year soared to 62. From 2010 onwards, Tesla's patent filings trended downwards, possibly because Tesla thought it had made a lot of progress on battery packs. So Tesla has instead focused its R\&D interests on areas such as electric motors and vehicle control. It's also possible that Tesla encountered a shortage of funding then. Even so, Tesla continues to maintain the pace of about 40 patent applications per year. As of June 1, 2015, Tesla's total global patent applications have reached 286. Now Tesla has over 400 patents.

Tesla has spent the last decade taking on rivals in the two key performance parameters of electric vehicle: acceleration and mileage and has an absolute competitive advantage on them. As 0 - $100 \mathrm{kph}$ acceleration, Tesla's Model series electric cars has progressed from 5.6 seconds to 2.5 seconds and even its electric Trucks can also break the three-second barrier. Tesla's 2010 S1 memo shows that the automaker wasn't yet able to commercially produce electric car with above 140 miles mileage, but back then Tesla set a goal of 300 miles. That goal seemed a bit ahead of schedule at the time, but put into today's perspective, it shows exactly what Tesla has accomplished in a decade. In 2020, Tesla applied for a new patent for a battery - a battery that has more than 5000 cycles of charge and discharge and a total of Lithium-ion battery modules with a lifespan of up to 1.6 
million kilometers, four times the battery life standard of mainstream electric vehicles. Accordingly, over the past decade, Tesla has been raising the bar and pushing the boundaries of the industry as technical support for its patented open source strategy. The result is an absolute technological advantage over competitors worldwide.

\subsection{Profit}

Tesla's entire vehicle sales are highly profitable. Munro \& Associates' 2018 report, The Tesla Model 3 Benchmark Report, notes that a \$50,000 high-spec Tesla Model 3, with hardware costs of $\$ 34,700$, logistics and labor costs of about $\$ 300$, so the profit is about $\$ 15,000$. The profit of a regular Model 3 is about $\$ 10,000$. Therefore, the gross margin of Model 3 is $30 \%$, and a net margin of which is about $15 \%$. In contrast, other car companies, the gross margin of Toyota and Honda are less than 20\%, while some German and French car companies' gross margins are often only about $10 \%$, hardly even close to Tesla's net margin.

\subsection{Technology Standards Promotion}

Traditional technology companies have used patent pools and patent alliances to construct patent barriers to serve their markets. And no matter how advanced a patent is, it is only valuable if it is fully used. Tesla understands this, and has liberalized the use of patents through a patent open source strategy, and is practicing the Internet's great spirit "free, equal, open and share". At the same time, Tesla grasps the high point of technology standards and uses its own open source patents to open up more and more potentialpatent pools to create a "shared, rapidly evolving technology platform". On the other hand, Tesla combines software (Tesla technology patents and technology standards) with hardware (Tesla electric vehicles and charging stations), creating a strong Tesla ecosystem. The more companies that use Tesla's technology, the higher market share Tesla grabs, and the more Tesla's technology is recognized, and its brand value has increased accordingly. The increase in goodwill has strengthened investor confidence while winning the consumer market for Tesla. Tesla is standing tall amid chronic losses.

Charging stations are also an important tool that Tesla relies on to promote technology standards. As mentioned above, Tesla has deployed 1870 supercharging stations and 16,585 fast charging piles worldwide. Ostensibly, Tesla's move is to provide convenience to its customers and promote the sale of its own electric vehicles. In reality, for those electric vehicles companies interested in Tesla, they mustuse Tesla's already open-source technology patents as long as they use off-the-shelf fast chargers deployed by Tesla. They also accept the technology standards that go with it, especially in terms of charging.

Tesla is definitely not without rivals when it comes to charging technology. Challengers like Lucid in the US and Porsche in Germany are positioning themselves in the premium electric sports car market with their Lucid Air and Porsche 
Mission E, but both of them have not officially released yet. On the contrary, Tesla has not only achieved mass production of various types of electric vehicles, but also deployed a large number of fast charging stations around the world. In terms of technology alone, even if Tesla's charging technology is surpassed, Tesla is still able to take advantage of its huge fast charging base and mature fast charging system and technical cooperation platform to continue to maintain competitive advantage.

\section{Problem in Practice}

Unlike other high-tech companies, Tesla, while also aggressively pushing technology development and seeking worldwide patent placement, is instead of serving their market by building patent barriers or patent alliances but chooses the patent open-source model for their business success. From Tesla's point of view, we can approximately conclude some major difficulties in this model. Briefly, it is a hardship among technology, finance, and production.

High-tech enterprises belonging to same patent alliance often build patent pools or clusters together so that they can learn from each other and improve overall strategic competitiveness. Tesla neither joins any patent alliance nor holds as many patents as traditional car companies like Toyota, who has had over 20,000 patents related to all kinds of new energy vehicles, thus it needs to maintain technical advantage in the battery, motor and electronic control and other electric vehicle core technology areas at all times, and through the continuous iteration of technology research and development updates, step by step to push up the industry's technical threshold and ultimate.

Tesla has had a significant technological advantage for more than a decade, but Tesla's competitors are also growing up. Tesla's competitors have been catching up on technology, getting closer in some key areas such as car power and charging speed, and even overtaking Tesla, making it increasingly difficult to maintain the lead. For example, Tesla's BMS battery management system faces competition primarily from GM, while Tesla's highly publicized Autopilot Technology that isn't as efficient and reliable as the GM Super Cruise and Infiniti L2. Once Tesla lost its technological edge, not only will it affect its own technology to seize the high ground of standardization, but it also won't be able to use its own open source strategy to attract more patents, and the technical platform Tesla designed will eventually go bankrupt.

Tesla's opening its patents for free use does not mean unconditional. Users also need to comply with the general agreement of patent open source, like Tesla's opening the source code of the software developed by Linux Kernel tool, they will open-source all the patents it owns related to the Tesla patents they used. In this way, Tesla uses its own patents to open several large and potential patent pools for free use by itself and the industry, which is in line with the Tesla's vision of creating a "shared, rapidly evolving technology platform". Although patent users don't have to pay for Tesla's patents, they are tied to Tesla's 
technology platform firmly, while Tesla cannot be sued on any intellectual property grounds, nor trademark infringement or trade secret violation. These will lead to the risk that users may face the loss of their own rights and interests and reduced strategic competitiveness of the enterprise.

For Tesla, open source means the technology and patents that has been invested heavily in R\&D cannot be directly transformed into capital flows through patent licensing, which exacerbates the imbalance in the distribution of capital flows to Tesla. Tesla has been in deficit most of the time since its IPO, with only 2013, 2016 and 2018 achieving revenue and net profit growth accelerated, corresponding to the second year of production of the Model S, Model X and Model 3 , respectively. If Tesla's ability to create a flow of money through financial means wasn't strong enough, it might have gone bankrupt long ago.

Capacity bottleneck is something Tesla can't ignore, which remains a major constraint to Tesla's development, posing new challenges to Tesla's ability to integrate supply chain strengths and resources. The global electric vehicle market suffered a cold winter in 2019, with annual sales of 2.21 million units, up 10 percent year-on-year and well below the $65 \%$ in 2018. Back then, Tesla sold 360,000 units worldwide and produced only 350,000 units, leaving a capacity gap of about 10,000 units. Tesla can encounter capacity bottleneck even during industry winter, and is unlikely to be able to handle the likely market growth in the coming years. What's more, without enough capacity, orders can't be delivered in time for Tesla to collect the final payment, and Tesla will need to continue to raise money to maintain a stable cash flow. This will not only increase the cost and risk of accessing capital, but will also correspondingly affect the business model based on its patent open source strategy negatively. These are all things that Tesla needs to worry about.

The final procedure of Tesla's business model is the whole vehicle business. In addition to some of the negative factors analyzed earlier, Tesla is also facing challenges in the whole vehicle business. At present, many local new electric vehiclecompanies supported by China, such as Xiaopeng and NIO, generally have both strong power performance and long mileage closing to Tesla, but with more competitive price. Plus, in 2020, Tesla is affected by negative information such as hardware downgrade scandal in China, which greatly affects Tesla's reputation and offends its customers. If the feedback result of these negative factors is a decline in vehicle sales and a decrease in market share, Tesla's sales, profitability and capital flow back will be negatively affected, and the sustainability of Tesla's patent open source strategy will be affected as well.

\section{Conclusion}

The concept of open source originates from the computer industry, usually refers to the software source code open source. The patent open source represents a new way of intellectual property protection. Compared with the traditional means of patent protection, such as patent pools, patent open source changes the logic 
of intellectual property protection, has more emphasis on technology sharing, eliminating the cumbersome process of patent negotiation and licensing, greatly facilitating the application of patented technologies. And from the perspective of the market game, patent open source can attract large-scale participants and promote other peers to choose it, which helps to promote the healthy development of the industry. Following Tesla, Toyota is correspondingly releasing its patents on fuel cell vehicles in a bid to emulate the Tesla's strategy and seize the next high ground in new energy vehicles.

Commonly, the value of patent open source cannot be intuitively recognized because open-sourced patents cannot bring direct benefits through patent transferring or licensing for enterprises. However, patent open source can be an important part of a company's business strategy and have a positive impact on the company. As can be seen from the case of Tesla, the main contributions of open source patents are to improve goodwill, unify technology standards, and help companies to attract more high quality technology patents for the "shared technology platform" and "Tesla's ecosystem". Therefore, the extension of patent open source to other high-tech industries often needs to be discussed with the actual business strategy, so that the value of patent open source can be clearly recognized.

Through the pursuit of advanced technology and unparalleled research and development capabilities, Tesla continues to break through the industry's utmost, firmly occupying a leading position in the industry as well as the high ground of technology standards competition, and then release the existing patents free to use. Tesla eliminates the complicated steps of traditional technology patent transfer, allowing everyone to make progress together and expand the market share of electric vehicles. On the one hand, Tesla exports technology standards through patent open source, making its own technology standards more universal. On this basis, Tesla goes on to lead the construction of charging facilities and the unification of charging standards, and so on are naturally not a problem. On the other hand, this process also improves Tesla's goodwill, stabilizes investors' confidence, ensures the continuity of corporate cash flow, and ensures that up sales of their own electric cars. And those who apply Tesla technology, while enjoying Tesla technology and facilities, can also benefit from Tesla's expanding market. At the same time, the company will open-source its relevant patented technology, adding bricks to the Tesla technology platform to achieve win-win cooperation as Tesla designed.

However, Tesla's patent open source strategy seems to uphold the Internet spirit, but actually does not go beyond the "technology standard monopoly". It is still essentially a mega-automotive company with the world's second largest market capitalization in the automotive industry with great technical, financial and management advantage of the industry, and constantly raise the industry's threshold and ultimate, to export technology standards and other means to plunder the global electric vehicle market. Meanwhile, Tesla, taking advantage of 
the general agreement on patent open source, can open more and more huge and potentially large patent pools with just a handful of its own patents, make them free for its own use in the name of building a "shared, rapidly evolving technology platform", and then use the advantages of unified technology standards, vehicle sales and so on to beat other competitors. Tesla's plan is not hard to arouse public's vigilance, which can be evidenced by the attitude of many countries' governments towards Tesla: China and some European countries have reduced or even cancelled the subsidy of cars targeted at Tesla, and are really cautious about Tesla's plans for both factory building partnerships and charging station deployment.

\section{Conflicts of Interest}

The authors declare no conflicts of interest regarding the publication of this paper.

\section{References}

Chen, Q. (2018). Practice and Value of Open Patenting License under the Sharing Economy. Forum on Science and Technology in China, 11, 86-93.

Du, K. et al. (2016). Tesla Patent Application Information Analysis. China High-Tech Enterprises, 7, 189-190.

Leveque, F., \& Meniere, Y. (2007). Copyright versus Patents: The Open Source Software Legal Battle. Review of Economic Research on Copyright Issues, 27.

Maggiolino, M. (2013). Standardized Terms and Conditions for Open Patenting. Minnesota Journal of Law Science \& Technology, 14, 785-951.

Taeihagh, A. (2017). Crowdsourcing, Sharing Economies and Development. Journal of Developing Societies, 33, 191-222. https://doi.org/10.1177/0169796X17710072 